\title{
Maternal Literacy and Child Health in Less- Developed Countries: Evidence, Processes, and Limitations
}

\section{Citation}

LeVine, Robert A., and Meredith L. Rowe. 2009. "Maternal Literacy and Child Health in LessDeveloped Countries: Evidence, Processes, and Limitations." Journal of Developmental \& Behavioral Pediatrics 30 (4): 340-349.

\section{Published Version}

doi:10.1097/DBP.0b013e3181b0eeff

\section{Permanent link}

http://nrs.harvard.edu/urn-3:HUL.InstRepos:13041198

\section{Terms of Use}

This article was downloaded from Harvard University's DASH repository, and is made available under the terms and conditions applicable to Other Posted Material, as set forth at http:// nrs.harvard.edu/urn-3:HUL.InstRepos:dash.current.terms-of-use\#LAA

\section{Share Your Story}

The Harvard community has made this article openly available.

Please share how this access benefits you. Submit a story.

\section{Accessibility}




\title{
Maternal Literacy and Child Health in Less-Developed Countries: Evidence, Processes, and Limitations
}

\author{
Robert A. LeVine, PhD,* Meredith L. Rowe, EdD†
}

ti: children's health and survival chances, particularly in the less-developed countries (LDCs) of Asia, Africa, Latin America, and the Pacific, however questions concerning the processes involved remain unsettled. This article examines what we know about maternal schooling and child survival, proposes the acquisition of literacy as a pathway of influence, and reviews evidence concerning how literacy skills acquired in school affect maternal health behavior critical to child survival.

The history of child survival in the LDCs during the second half of the 20th century is a dramatic one that is still being analyzed and interpreted. ${ }^{1}$ The average under-5 mortality rate of the LDCs decreased from 222 (per 1000 live births) in 1960 to 90 in 1999; the infant mortality rate alone dropped from 141 to 63 . Table 1 shows the magnitude and scope, also the variability, of this "child survival revolution," which was largely due to control of the infectious diseases (diarrheal diseases, including typhoid and cholera; acute respiratory infections, including measles and pneumonia; and other infections such as neonatal tetanus and malaria) - that had maintained high infant and child mortality levels in previous generations.

The LDCs were undergoing a massive socioeconomic transformation during the same period, with urbanization, economic growth, and the expansion of transportation networks, mass communications, and schools occurring on a large scale, although it was also variable across countries and regions. With so many concurrent changes going on and being tracked as never before by national censuses and surveys, and with the increasing availability of high-speed computers in the 1960s and 1970 s, social scientists examined the relationships of these trends to each other. National infant mortality rates, for example, turned out to be correlated with almost all indicators of socioeconomic development, and a country's infant mortality is often considered even nowadays to be a sensitive index of development. By 1980 , it had become clear that declining infant and child mortality rates were strongly associated with rising levels of household income and women's schooling, and that

From the *Harvard University Graduate School of Education, Cambridge, MA; †Department of Human Development, University Maryland, College Park, MD.

Address for reprints: Robert Alan Levine, $\mathrm{PhD}$, Harvard Graduate School of Education, Cambridge, MA 02138; e-mail: levine68@gmail.com

Copyright (c) 2009 Lippincott Williams \& Wilkins maternal school attainment was a predictor of reduced infant and child mortality in LDCs even when income and other socioeconomic factors were controlled. . $^{2,4}$ This finding, contradicting the earlier assumption that maternal schooling was simply a proxy for income and social status, set the stage for further investigations of maternal schooling effects on child survival.

Evidence from an increasing number of countries indicated that women's schooling was necessary if not sufficient to achieve child mortality reduction-a prerequisite for mortality decline. This view drew empirical support from the World Fertility Survey ${ }^{5,6}$ and the subsequent Demographic and Health Surveys (DHS),, 8 which were carried out on a large scale across the developing world. The World Fertility Survey and the DHS confirmed the finding that maternal schooling was independently associated with infant and child mortality, and they permitted a more detailed understanding of the complex relationships involved. For example, most of the effect of women's schooling on their children's survival chances during infancy was eliminated when income was controlled, but the effect on postinfancy child mortality remained strong. Many analyses not only replicated the schooling-mortality relationships in different settings but also showed schooling to be related to maternal behavior, particularly healthcare utilization and home hygiene practices.

The DHS data show that a mother's schooling is consistently associated with the chances that she will have prenatal care, that her births will be attended by trained medical personnel, that her children will be completely immunized, and that when sick they will receive timely and modern medical care. More educated women are more likely to take sick children to a medical facility than are less educated women. Whereas between one-quarter and one-half of the uneducated women took a sick child to a medical facility, approximately three-quarters of mothers with secondary schooling did so. An analysis of 17 DHS national datasets finds that, even after controls for economic and biodemographic variables are applied, failure to use prenatal care was at least 55\% higher among unschooled than among secondary-schooled women. Less spectacular but similar conclusions are drawn regarding the effects of women's schooling on the failure to use tetanus toxoid and child immunization. ${ }^{9}$

Some analysts suggest that these educational differentials in healthcare utilization constitute an intermediate 
Table 1. Infant Mortality and Under-Five Mortality Rates (Number of Deaths Per 1,000 Live Births, in the First 12 and First 60 Months, respectively) for 1960 and 1999, Developing Countries and Five Regions

\begin{tabular}{lccccc}
\hline & \multicolumn{2}{c}{$\begin{array}{c}\text { Infant } \\
\text { Mortality }\end{array}$} & & \multicolumn{2}{c}{$\begin{array}{c}\text { Under-Five } \\
\text { Mortality }\end{array}$} \\
\cline { 2 - 3 } \cline { 5 - 6 } & $\mathbf{1 9 6 0}$ & $\mathbf{1 9 9 9}$ & & $\mathbf{1 9 6 0}$ & $\mathbf{1 9 9 9}$ \\
\hline $\begin{array}{l}\text { Developing } \\
\text { countries }\end{array}$ & 141 & 63 & & 222 & 90 \\
$\begin{array}{l}\text { Latin America and } \\
\quad \text { Caribbean }\end{array}$ & 102 & 31 & & 153 & 39 \\
$\begin{array}{l}\text { Sub-Saharan Africa } \\
\text { South Asia }\end{array}$ & 156 & 107 & & 258 & 173 \\
$\begin{array}{l}\text { Middle East and } \\
\quad \text { North Africa }\end{array}$ & 148 & 74 & & 244 & 104 \\
East Asia and & 156 & 48 & & 247 & 63 \\
$\quad$ Pacific & 140 & 35 & 212 & 45 \\
\hline
\end{tabular}

Source: UNICEF: State of the World's Children 2001: Early Childhood, Table 1, p 81. New York: UNICEF.

link in a causal pathway from schooling to child survival, but empirical links to the survival and health outcomes are often missing. In other words, despite conclusive evidence that mothers with more schooling more frequently take actions designed to reduce the risks to their children's survival, only a few studies actually demonstrate that their actions are responsible for reduced mortality. One such study is a 1999 analysis of the Nepal Family Health Survey of 1996, showing that use of prenatal care is inversely related to infant mortality in a national sample of mothers. ${ }^{10}$ The Matlab project in rural Bangladesh showed that a medical outreach program eliminated differences in child mortality by maternal schooling (and concomitant health care utilization) among 12,266 children born in 1981 and 1982 and survived to 12 months of age. ${ }^{11}$

Demographic analysts, aware that maternal and child health care services in LDCs are often ill equipped and poorly organized and that the Western history of mortality decline points to other factors as crucial, are cautious about drawing the conclusion that maternal health care utilization is a necessary causal link between maternal schooling and reduced child mortality. But a substantial body of evidence like that cited earlier from Nepal and Bangladesh suggests that the contexts of mothers in the LDCs are very different from those of American and European mothers in the early part of the 20th century. In the latter case, there were co-occurring public health measures (purification of water, sewer systems and garbage disposal, and pasteurization of milk) that worked without special effort by the individual mother regardless of her education (although there were concurrent campaigns to advise mothers about health and hygiene). Such measures are lacking in most LDCs, where mothers must boil water-which schooled women are more likely to do-to make it safe for their children to drink, rather than having access to safe water from the tap. This

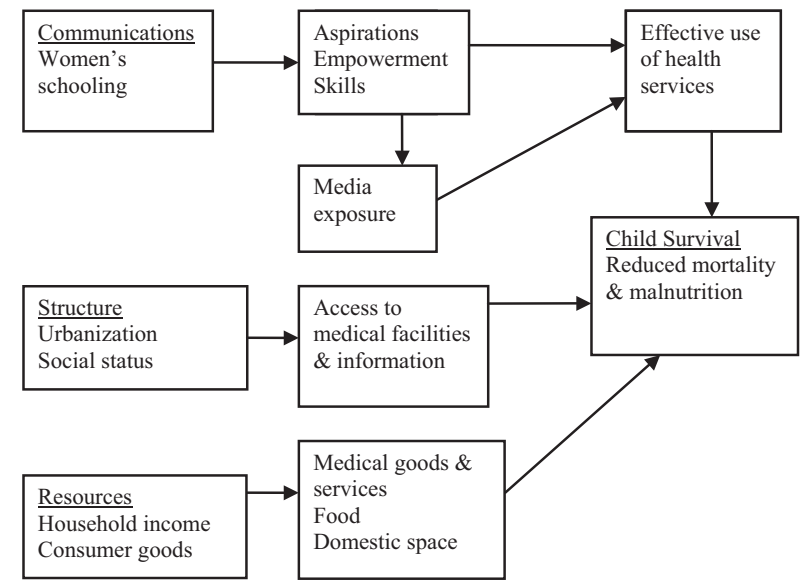

Figure 1. Pathways from changing condition to child survival in developing countries, 1950 to 2000.

greater burden on the mother's actions, with little help from the community or the state, makes it much more likely than in the West a century ago that maternal schooling will affect the health environment of the child. In other words, mothers in the LDCs are often rearing infants and children in domestic environments with health risks such as contaminated water, animal droppings, and unsafe foods, and it is up to the individual mother- usually in the absence of universal disease prevention measures by the state-to take protective action. This situation heightens the importance of what mothers do at home and in the clinic, increasing the impact of maternal schooling on child health.

Figure 1 summarizes some of the theoretical pathways that were proposed to account for the rise in child survival in developing countries during the second half of the 20th century, under the 3 headings of communications, structure, and resources.

Communications, which include women's school experience, involves at least 3 pathways. In one, schooling elevates a woman's status aspirations, leading her to marry a man of higher status or income, with her husband's advantages benefiting their children's survival chances. The second pathway is based on the idea that women become psychologically empowered by schooling, acquiring the social attitudes (autonomy, assertiveness) needed to become more active agents on behalf of their children's health and welfare. Thus women who without schooling would be controlled by their motherin-laws, even about matters of children's health, are likely to assume a more active role in health care as the result of schooling. A third pathway involves skills learned in school that make women more capable of acting on behalf of their children in health and nutrition matters, reflecting either a direct effect of school learning on behavior in health situations or an indirect effect through the mass media, as elaborated later in this article. The World Bank's World Development Report 1993: Investing in Health attributes the effects of maternal schooling on infant and child mortality to women's "vital role in creating healthy house- 
holds," including the schooled women's greater use of prenatal care and delivery assistance, keeping homes and children "tidier and cleaner than uneducated women," and being better at "getting information on health and acting on it," including the use of oral rehydration therapy for children with diarrhea, but the report does not specify whether this behavior is due to skills learned or attitudes shaped in school. ${ }^{12}$

Structure, which refers to aspects of social structure that provide better access to health services or other facilities like safe water, can mean either geographical access through residence (usually in an urban center where health facilities are nearby) or social access through membership in a class or caste with social connections to health care practitioners.

The resources category refers to money and other material goods that can improve the health environment of a child. The income effect on child mortality, mentioned earlier, has been estimated to account for half of the maternal schooling effect. Thus, women with a higher household income are better able to provide a spacious and sanitary home stocked with useful medications, to use private doctors when needed, and to pay for rapid transportation to a clinic in an emergency.

The causal pathways portrayed on Figure 1 represent models of how child survival improved, models that have gained plausibility from qualitative as well as quantitative research. Some are more speculative, others better confirmed by data. The evidence as a whole suggests that all 3 categories jointly contribute to the processes that lead to variations in child survival across individuals, countries, and historical periods, and that multivariate analyses investigating the effect of one should control for the effects of the others.

In an analysis by historical period, the DHS data on 13 African countries between 1975 and 1985 show that a $10 \%$ increase in female literacy rates reduced child mortality by $10 \%$, whereas changes in male literacy had little influence. DHS data in 25 developing countries show that, all else being equal, even 1 to 3 years of maternal schooling reduces child mortality by about $15 \%$, whereas a similar level of paternal schooling achieves a $6 \%$ reduction. The effects increase when the mothers have had more education; in Peru, for example, 7 or more years of maternal schooling reduces the mortality risks nearly $75 \%$, or about $28 \%$ more than the reduction for the same level of paternal schooling. Countries that in 1965 had achieved a near-universal enrollment of boys but much less for girls had about twice the infant mortality in 1985 of countries with a smaller boy-girl gap. ${ }^{12}$

This seems convincing, although it does not specify the intervening linkages. A review published as recently as 2006 concludes that the mechanisms driving the consistent relationship of maternal schooling with child health have yet to be fully understood. ${ }^{14}$

In other words, the pathways and processes through which the schooling of women influences child health and survival remain in question. The continuing uncer- tainty about how maternal schooling works undermines confidence in its status as a cause of improved child survival. ${ }^{15}$ This problem has been recently clarified by Ní Bhrolcháin and Dyson, ${ }^{16}$ who point out that the experiments or policy interventions using randomization that establish causal relationships in other disciplines are rarely possible in demographic research, which must use other methods. They propose criteria for determining whether a factor is a cause of a demographic event or trend, and one of the essential criteria is "mechanism": "to establish a link, a plausible set of intermediate links is required showing how the cause brings about the effect. Specifying and providing evidence of the mechanism involved is essential." 16

This article presents evidence of a possible causal pathway from women's schooling to child survival through literacy, indicating that literate communication skills acquired in school during childhood-even in lowquality schools - can improve a woman's health navigation skills as a mother and lead to better outcomes for her children. Our approach to identifying literacy as a mechanism of the school effects is to determine whether literacy mediates the relation between schooling and the maternal behaviors that have been empirically or conceptually linked to child survival. We use the term "mediate" in its statistical sense to refer to the situation where the relation between a predictor variable (e.g., schooling) and an outcome variable (e.g., maternal health behavior) can be explained by a mediator variable (e.g., literacy). The implications of this evidence for maternal and child health policy and practice are explored in the latter part of the article.

\section{LITERACY: DEFINITION AND MEASUREMENT}

The place of literacy in population studies related to health is unsettled: one group of analysts simply presumes that literacy links school experience with maternal behavior, using the term "literacy" as equivalent to "education," "schooling," and "educational attainment" and taking schooling as a proxy for literacy. Another group of analysts explicitly considers a literacy link but rejects it as implausible. They argue that the inadequacy of schools in many less-developed countries precludes literacy instruction of a quality that could explain the strong maternal schooling-health relationships, and also that the consistency of those relationships across levels of schooling is incompatible with the threshold expectable if literacy were involved. Neither group of analysts has attempted to test its assumptions by measuring mothers' literacy directly.

Meanwhile, the multidisciplinary study of literacy advanced greatly during the closing decades of the 20th century. Literacy was reconceptualized in cognitive, social, and cultural terms, ${ }^{18}$ leading to research that invalidated the assumption that adults could be classified as literate or illiterate based on whether they had attended school for at least 5 years - the assumption on which national literacy rates had been calculated. Reading com- 


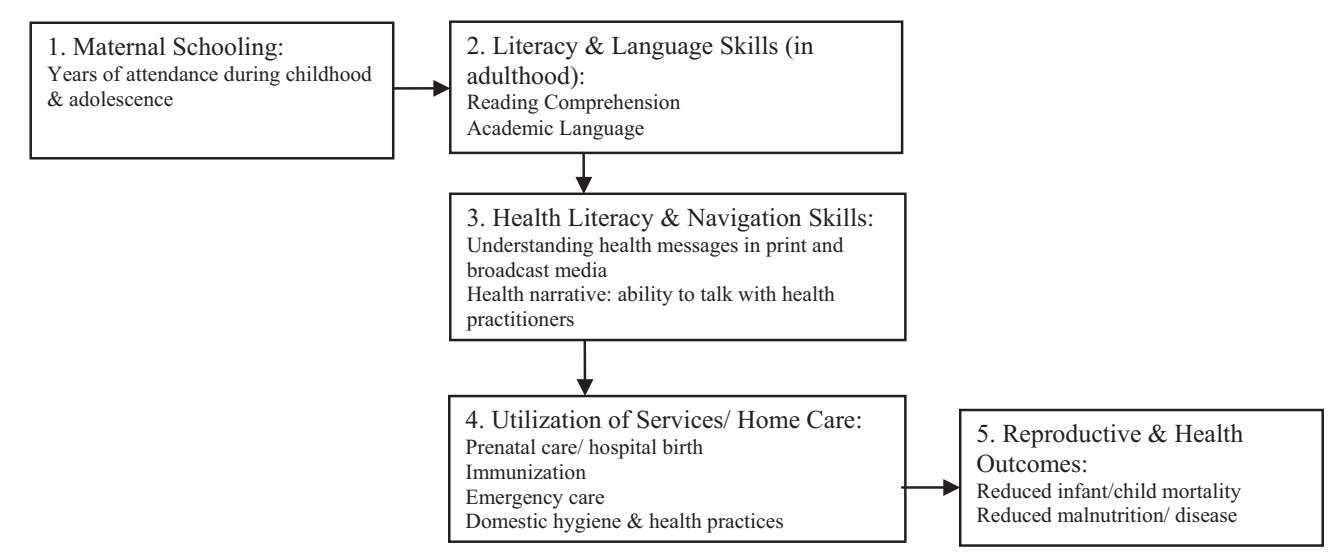

Figure 2. Pathway from maternal schooling through literacy skills to child health outcomes.

prehension, for example, continues to improve up to the postsecondary level of schooling, through the mastery of more difficult texts, ${ }^{19}$ rather than leveling off at a particular threshold; it cannot be ruled out as a correlate of child survival variations throughout the educational range. Furthermore, the literacy skills acquired in school go beyond reading and writing to include forms of oral discourse based on written texts, particularly a specialized speech register involving superordinate or abstract terms and explicit descriptions that do not presume a shared context. ${ }^{20}$ Mastery of this school-based speech register can be thought of as "academic language proficiency"; it contrasts sharply with conversational speech but resembles the discourse of other bureaucratic settings such as hospitals and health clinics. This proficiency is tied closely to children's school performance in Western settings, and like reading comprehension, it improves continuously throughout the educational range.

These findings from literacy research suggested the theoretical model of a literacy pathway leading from maternal schooling to child health, as portrayed by Figure 2 . In this chart, as girls attend school, they acquire proficiency in reading and academic language that improves their communication skills relevant to health, i.e., their ability to understand public health messages in the mass media and to interact effectively with medical practitioners (e.g., providing an organized health narrative, following medical advice, navigating a hospital environment). By using these skills as mothers, women with more schooling are better able to gain protective resources for their children from the bureaucratized health care institutions of a changing society. ${ }^{21}$ In emphasizing literacy skills as enabling factors for health care behavior, we do not ignore the importance of motivation for using skills or dismiss the possibility that maternal schooling can also affect a woman's aspirations, empowerment, and autonomy. We are hypothesizing, however, that such social attitudes as effects of schooling are likely to be variable across countries and regions and even from one birth cohort of women to another within the same country as schooling becomes more widespread, whereas communication skills might be more stable as outcomes of school experience that affect health interactions. Thus, literate communication skills may be more likely than social attitudes to explain the remarkably consistent relationships of women's schooling with health outcomes across lessdeveloped countries varying in their traditional cultures and levels of socioeconomic development.

\section{RESEARCH FINDINGS ON MATERNAL LITERACY AND HEALTH CARE BEHAVIOR}

This section reviews evidence from 3 studies that have attempted to test the theoretical model of Figure 2 by direct assessment of women's literacy and language skills: the Guatemala study of Gorman and Pollitt, the 4-country study (Mexico, Nepal, Venezuela and Zambia) of the Project on Maternal Schooling at the Harvard Graduate School of Education, and the Nepal survey conducted jointly by UNICEF Nepal, the Centre for Educational Research and Innovation in Development at Tribhuvan University and the Project on Maternal Schooling at the Harvard Graduate School of Education.

\section{The Guatemala Study}

The Instituto de Nutricion de Centroamerica y Panama (INCAP) study was a longitudinal investigation of the effects of nutritional intervention conducted from 1969 to 1977, with a follow-up in 1988 to 1989, by the INCAP in 4 rural villages (total population: 3200) in eastern Guatemala. The INCAP study was unique among the major biomedical research projects conducted in the less-developed countries during the second half of the 20th century, including psychologists in planning the research and measuring the cognitive effects of malnutrition on children. Cognitive measures were collected from children in the original study, and literacy was tested and school records collected in the 1988 to 1989 follow-up. Findings concerning literacy and health care can be summarized in 3 propositions:

1. School attainment predicts subsequent literacy performance, with socioeconomic factors and preschool cognitive performance controlled. ${ }^{22}$ The data show that children can acquire basic literacy skills even from small amounts of schooling and can retain them 
into adulthood. Furthermore, although the literacy criterion may have been set at a low level, the study is unusual in being able to control for directly assessed preschool cognitive abilities, indicating that schooling rather than selection by ability influenced the literacy score.

2. "Literacy skills continued to improve after children left school and subjects with the fewest number of years of schooling completed appeared to have improved the most." 22 This demonstration that small doses of schooling may leave a child with literacy skills that continue to improve (presumably with use) indicates that literacy learning could be involved in the evidence linking maternal school attainment with behavioral, health, and demographic outcomes.

3. Mother's literacy predicts 4-year-old child's respiratory illness, with maternal schooling and SES controlled. Among 266 mothers in the INCAP study whose children's respiratory illness was monitored weekly for the first 4 years of life, maternal literacy (directly assessed) was significantly associated with less respiratory illness of 4-year olds, controlling for maternal schooling (1-3 yr vs. 4-6 yr) and an index of socioeconomic status. ${ }^{24}$ Maternal literacy combined with maternal schooling and socioeconomic status accounted for only $8 \%$ of the variance in respiratory illness, but this is unprecedented evidence of a significant link between maternal schooling and child illness through literacy.

The INCAP study shows that small amounts of maternal schooling can affect child health in a positive way, and it provides evidence that literacy acquired in school is retained in adulthood and may be one pathway that links maternal schooling with child health. Thus, it provides strong evidence of the causal influence of schooling on literacy (boxes 1 and 2 on Fig. 2) and suggestive evidence of the causal influence of both maternal literacy and schooling on child health (boxes 1 and 2 with 5 on Fig. 2), although evidence of intervening maternal behaviors is missing.

\section{The Project on Maternal Schooling of the Harvard Graduate School of Education}

This project conducted field studies in 4 countries (Mexico, Nepal, Zambia, and Venezuela) from 1983 to 1998. Having been published in journal articles, the findings are now being brought together as a book. ${ }^{25}$ The initial fieldwork was in Cuernavaca, Mexico (1983-1985), exploring varied processes that might link women's schooling with maternal behavior outcomes in a low-income urban sample of 333 mothers. ${ }^{26}$ By 1989, we had decided to focus on the role of literacy as a mediating influence of schooling on maternal reproductive and health behavior. During the 1990s, we conducted studies in Tilzapotla, a rural town in Morelos, Mexico ${ }^{27}$; Chifubu, an urban neighborhood in the copperbelt town of Ndola, Zambia ${ }^{28}$; Goda-
Table 2. 1999 Under-Five Mortality Rates and Adult Female Literacy Rates for Four Countries: Mexico, Venezuela, Zambia, and Nepal

\begin{tabular}{lcc}
\hline & $\begin{array}{c}\text { Under-Five } \\
\text { Mortality Rate }\end{array}$ & $\begin{array}{c}\text { Adult Female } \\
\text { Literacy Rate }\end{array}$ \\
\hline Mexico & 33 & 80 \\
Venezuela & 23 & 90 \\
Zambia & 202 & 70 \\
Nepal & 104 & 14 \\
\hline
\end{tabular}

Source: UNICEF: State of the World's Children 2001: Early Childhood, Table 1, p 81. New York: UNICEF.

vari and Patan, rural and urban communities, respectively, of Lalitpur District, Nepal, in the Kathmandu Valley $^{29}$; and La Silsa, an urban barrio of metropolitan Caracas, Venezuela. ${ }^{30}$

Table 2 shows the under-five mortality rates and adult female literacy rates of the 4 countries at the end of the century. In female literacy, the 2 Latin American countries are very high, Nepal very low and Zambia intermediate. The same could be said for under-five mortality, except for the major rise in Zambia due to the spread of HIV/AIDS, hepatitis, and drug-resistant malaria. In urbanization (not shown), Mexico and Venezuela are also highest, Nepal the lowest, and Zambia intermediate.

Each study was designed as an independent replication, testing the same hypotheses linking schooling with health literacy and navigation skills through school-acquired literacy, but under different conditions. The particular sites chosen within each country were rural communities and/or urban neighborhoods of contiguous households, where women of varying levels of school attainment lived as neighbors. The primary criterion for community selection was wide variation in women's schooling, so that each sample could include mothers ranging from no schooling to the secondary or postsecondary levels while living in the same locality. The second criterion was that the community selected be situated in a district or province in which multivariate analyses of census or large-scale survey data had already shown mother's schooling to be independently related to child survival or maternal health behavior variables such as prenatal care. This meant our small-scale studies could focus on intervening processes involving literacy in a population known to be characterized by the familiar maternal schooling effects on health outcomes.

In analyzing the data, we treated school attainment as a continuous variable from 0 to 16 or more years rather than in terms of 3 or 4 levels (none, incomplete primary, complete primary, and secondary), thus using quantitative information on schooling that goes unused in the cruder categorical analyses that are conventional in demographic and epidemiological research. We investigated the local conditions of women's schooling, family life, and health care practices ethnographically and historically so as to be able to interpret the survey results in context.

The major weaknesses of our design for the identification of causal pathways were that women had not 
been randomly assigned to differing levels of school attainment, and the one-time survey meant using crosssectional data, i.e., women at differing levels of school attainment, to represent long-term temporal processes, rather than collecting longitudinal data on each woman before, during and after schooling (as approximated in the INCAP study). We attempted to reduce the resulting interpretive ambiguities concerning causal direction by combining statistical procedures (multiple regression modeling) that enabled us to control for rival hypotheses with the use of contextual (i.e., ethnographic and historical) data for interpreting the quantitative findings.

Samples in the 5 sites ranged from 78 to 161 mothers, who completed tests of reading comprehension and academic language (noun definitions), health comprehension tasks (oral and print), a health narrative task, and an interview on socioeconomic household characteristics. The findings were as follows:

School attainment in childhood and adolescence predicts adult literacy skills (reading comprehension and academic language) with socioeconomic factors controlled. The mothers' literacy, i.e., their performance on the tests of reading comprehension and noun definitions (academic language), was highly correlated (.5 or higher) with the grade at which they left school, as shown on Table 3. But their performance was also correlated, although not so highly, with age (negatively) and factors of socioeconomic advantage such as parents' schooling, husband's schooling, and household income (positively), suggesting that the correlations shown on Table 3 could be reflecting other variables correlated with schooling. This called for multivariate analysis to control for the other variables. The findings from each of the five samples showed that the schooling predicted literacy skills even when age and socioeconomic factors were controlled, and the regression models accounted for $28 \%$ to $71 \%$ of the variation in literacy skills.

These findings suggest that literacy was acquired in school and retained into adulthood, but they are also consistent with a rival interpretation, that girls of greater innate ability, or at least ability manifest before they attended school, progressed further in school and did better on literacy tests in adulthood, thus revealing the results of selection rather than environmental influence.

Table 3. Estimated Simple Correlations of Maternal Schooling With Reading Comprehension and Noun Definitions, in Five Diverse Samples

\begin{tabular}{lcc}
\hline & $\begin{array}{c}\text { Reading } \\
\text { Comprehension }\end{array}$ & $\begin{array}{c}\text { Noun } \\
\text { Definitions }\end{array}$ \\
\hline Mexico $(\mathrm{n}=78)$ & $.50^{* * * *}$ & $.76^{* * * *}$ \\
Nepal Urban $(\mathrm{n}=86)$ & $.79^{* * * *}$ & $.77^{* * * *}$ \\
Nepal Rural $(\mathrm{n}=81)$ & $.72^{* * * *}$ & $.66^{* * * *}$ \\
Zambia ( $\mathrm{n}=157)$ & $.52^{* * * *}$ & $.50^{* * * *}$ \\
Venezuela $(\mathrm{n}=161)$ & $.58^{* * * *}$ & $.54^{* * * *}$ \\
\hline
\end{tabular}

***** $P<.001$
Ethnographic evidence, however, indicated that differential school attainment during the period of the women's attendance was based not on academic ability manifested in school performance but on the timing of parental decisions to withdraw girls from school for their domestic labor (especially infant care), early marriage, or other family reasons (e.g., residential mobility), regardless of how well they were doing academically; the schools were in any event promoting all students from grade to grade until late in secondary school. ${ }^{31}$ Thus, the selection hypothesis, although it could not be falsified quantitatively, was not credible in any of the local contexts, leaving the conclusion that amount of school experience was the only plausible explanation for the women's assessed literacy skills and indicating a substantial (if far from perfect) retention of the literacy skills learned in school.

A second body of findings showed that maternal literacy skills predict comprehension of printed and radio health messages, with school attainment and socioeconomic factors controlled in all 4 countries. This suggests that literacy skills acquired in school mediate the effects of schooling on a woman's ability to understand public health messages in the mass media. Although it may be expectable that women who can read better (as the result of schooling) would be better able to read and understand printed health material, it is remarkable that literacy skills also influence the ability to comprehend radio health messages, which require no reading. In Nepal, for, example, where radio was important in disseminating public health messages, analysis of the total sample (rural and urban) showed that adding literacy to the regression model predicting radio message comprehension produced a highly significant effect of literacy, eliminated the significant effect of maternal schooling, and increased the variation accounted for $\left(\mathrm{R}^{2}\right)$ from $40 \%$ to $52 \%$. Literacy is clearly mediating the effect of schooling on listening comprehension, indicating that the mastery of oral discourse forms is part of the package of literacy skills transmitted by schools.

Furthermore, maternal literacy skills predict a woman's ability to formulate an organized health narrative in a clinic-like situation, with school attainment and socioeconomic factors controlled. In both Venezuela and Nepal-the opposite extremes in terms of level of women's school attainment-schooling was a significant positive predictor of a mother's ability to tell an organized narrative about her own or her child's illness, with socioeconomic factors controlled. In both countries, when literacy was included as a mediating variable, the effect of schooling reduced to nonsignificance, and literacy was a significant predictor of narrative organization. For example, in Venezuela, the model with schooling and controls explained $18 \%$ of the variation in narrative organization, and the $\mathrm{R}^{2}$ increased to $24 \%$ on the inclusion of literacy in the model. Thus, literacy skills not only relate to a woman's ability to understand oral health messages in the media as noted earlier but also predict 
her ability to orally describe a health-related event or illness in an organized and coherent manner.

Taken together, these results suggest that with increased formal schooling women develop better literacy skills that enable them to gather and provide necessary information relevant to their children's health and development, interacting more successfully with the health care system as both recipients of advice and participants in clinical processes. The next study builds on these findings and explores additional outcome measures of maternal health knowledge and behavior.

\section{UNICEF Nepal Survey}

In April 2000, UNICEF Nepal conducted, in collaboration with the Centre for Educational Research and Innovation in Development of Tribhuvan University and the Project on Maternal Schooling of the Harvard Graduate School of Education, a literacy and health survey of 2,000 residents of 2 districts of Nepal outside the Kathmandu Valley. ${ }^{32}$ This was a follow-up of the aforementioned study conducted by the Harvard group in Lalitpur District within the Kathmandu Valley, Nepal's most urbanized and developed region in terms of commercial development, education and health services. By conducting a survey in the more rural and less-developed Kaski and Chitwan Districts, it was possible to discover whether findings of the 4-country study could be replicated there, while testing additional hypotheses and using a somewhat different approach to literacy assessment, carried out under different conditions and with a larger sample. The literacy instrument of the UNICEF Nepal Survey included additional scales to assess arithmetic skills and other literacy abilities, but it did not include measures to assess academic language. There were also assessments of health knowledge, health behavior (self report), and media exposure.

In the sample of 2,000 , there were 482 mothers of children 12 to 60 months of age. These mothers had an average of 4.2 years of schooling but ranged widely: almost $37 \%$ had never been to school, but $23 \%$ had 9 or more years of school. Analysis of their interview and assessment data showed the following:

1. Maternal school attainment is correlated with maternal literacy, at a level similar to that of the Lalitpur rural sample $(r=.73, p<.001$; with age controlled, $r=.71, p<.001)$. The literacy test in this study measured reading, writing, and arithmetic and in all 3 areas tapped skills ranging from functional (e.g., recognizing letters and numbers) to academic (e.g., reading comprehension and solving word problems). A fine-grained analysis of the relation between schooling and literacy scores on this test showed a steady linear increase from functional to basic to academic skills with increases in schooling level. These findings provide further evidence for the robust relation between schooling and literacy skills and highlight the added benefit of measuring literacy skills directly rather than assuming that some amount of schooling (e.g., $5 \mathrm{yr}$ ) is equivalent to being literate.

2. Maternal literacy and media exposure mediate part of the effect of schooling on health knowledge. Heath knowledge is a composite measure including mothers' knowledge of vaccines, contraceptives, uses of medicines, and causes and preventions of HIV/AIDS. Mothers varied widely in their health knowledge, which was significantly related to years of schooling $(r=.57, p<.001)$, literacy skills $(r=.54, p<.001)$, and media experience measured as the frequency with which a mother reads magazines or newspapers, listens to the radio, and watches television $(r=.45, p<.001)$. Multiple regression analyses revealed that, controlling for district residence (urban or rural) and household wealth (both of which were significant predictors), maternal schooling was a significant positive predictor of health knowledge $(p<.001)$. Furthermore, when literacy skills and media experience were included in an additional model, the schooling effect reduced by almost 50\% (but remained significant), and literacy and media exposure were additional significant predictors of maternal health knowledge (total $R^{2}=43 \%$ ). These findings further implicate literacy as a mechanism explaining the effect of schooling on health knowledge. In addition, they also highlight media exposure as an important factor. This is not surprising, given the many public health campaigns in Nepal designed to communicate to audiences of all schooling levels through the broadcast media.

3. Maternal health knowledge is a significant predictor of maternal health behaviors, controlling for schooling, literacy skills, media exposure, and controls. Maternal health behavior was the sum of the mother's responses to specific items, including whether or not she received prenatal care or took iron tablets during pregnancy, whether she delivered her last child in a health facility, whether she keeps medicine in the home, and whether she treats unsafe water by boiling and/or filtering. The finding of health knowledge as a predictor of health behavior supports the idea of a pathway from a mother's health knowledge to her child's health care, and together with findings 1 and 2, it lends additional support to the pathway from schooling and literacy to health outcomes shown on Figure 2.

\section{CONCLUSIONS: WOMEN'S SCHOOLING-A NECESSITY, BUT NOT A PANACEA}

Thirty years of research on data collected throughout Africa, Asia, and Latin America have confirmed the original findings of Caldwell that women's schooling was robustly associated with, and a possible determinant of, 
child mortality reduction in the less-developed countries (LDCs) during the second half of the 20th century. The evidence shows definitively that a mother's schooling - at high and low levels of education, in cities and villages, under diverse economic conditions-is related to the chances of her child's survival. There is also a good deal of evidence indicating (less definitively) that maternal use of health services and home health and sanitary practices helped bring about the improved child survival associated with women's schooling. Overall, the research points to 3 major socioeconomic pathways of influence, involving communications (schooling and the mass media), structure (urbanization and status), and resources (income, consumer goods) as having collaborated to bring mortality rates down. There may be a synergy among these causes such that the effect on child survival of their acting jointly is greater than the sum of their separate effects. More research is needed to test such causal models of mortality determination; they remain plausible theories supported by partial bodies of evidence. In any event, when structural and resource factors are controlled by sampling or multivariate statistical analysis, schooling is consistently shown to predict child survival variables, particularly postinfancy child mortality and maternal healthcare utilization, in a wide range of LDCs.

The big knowledge gap concerns the linkage between attending school in childhood and adolescence and effective maternal health behavior: what is the process through which the former leads to the latter? Demographic analysts have offered conjectures, but little evidence, about how school experience shapes girls' development toward the kind of maternal behavior that improves their children's chances of survival (the top part of Fig. 1). Some have proposed that girls acquire social attitudes (aspirations, assertiveness or self-confidence, autonomy, and empowerment) in school which influence their behavior as mothers. This seems plausible in some contexts, but there is no body of comparative evidence, indicating that this kind of attitude change is consistent enough across the developing world to explain the widespread linkage between women's schooling and child survival. The cultures of some regions like Southeast Asia (e.g., the Philippines), for example, favor women's autonomy to a much greater degree than those of South Asia (e.g., India, Bangladesh, and Pakistan), where women are more socially constrained, however the school effects are evident in both regions. In Mexico, we found that those in the small, early cohorts of women who attended school felt empowered by it, but not those in the cohorts 40 years later when most girls were attending school for 9 years. In any event, measuring social attitudes validly and comparably among (nonuniversity-educated) peoples in such diverse contexts poses methodological problems that have not been solved.
In this article, we have proposed a literacy pathway from schooling to maternal health care (Boxes 1, 2, and 3 on Fig. 2) and examined its validity in studies using direct assessment of literacy skills in Guatemala, Mexico, Nepal, Venezuela, and Zambia. We found support for a literacy mediation hypothesis, i.e., that a woman's literacy skills mediate the effects of schooling on her health care related to infant and child survival. Several findings are particularly noteworthy:

- Women whose schooling was limited to a few years in schools of low quality nevertheless retain literacy skills into their child-bearing years.

- The directly assessed literacy skills of mothers predict their health literacy and health navigation skills, i.e., their abilities to read printed health messages, comprehend radio health messages, present an organized health narrative (as in a clinic), and perform effectively on a health knowledge test, even with schooling and socioeconomic factors controlled. It is clear that literacy acquisition in school bolstered not only reading skill but also oral listening and narrative abilities and the capability to learn health information from the mass media. In the UNICEF Nepal survey, maternal literacy, health knowledge, and media exposure were shown to influence (self-reported) maternal health behavior.

- These findings of literacy mediation are robust in that they were replicated in diverse populations and contexts, using 3 different methods of literacy assessment (one for the 4-country study, separate ones for the Guatemala and UNICEF studies), and revealing effects at different levels of school attainment that correspond to the levels at which mortality differentials have been found.

Thus, the literacy mediation data support those parts of the causal pathway from schooling to child survival that are displayed as linking boxes $1,2,3$, and 4 on Figure 2. These studies did not measure mortality itself (box 5), most of the samples being too small, but the research was carried out in populations where the school-mortality and school-utilization links had been already established.

Given the difficulty of demonstrating causation in field research of this kind, it cannot be claimed that the case for literacy mediation has been definitively proved. Larger and longer studies, conducted in even more places, would help. But the literacy research reviewed earlier has exposed to empirical view a process intervening between women's schooling and child survival that might explain the widely found relationship. No alternative account of an intervening process has received this amount of empirical support.

Literacy skills and the health skills they foster are learned competencies involving cognitive abilities that do not operate alone to improve child health or prevent morbidity or mortality; the person who has the competence must be motivated to use it and situated in a facili- 
tating environment. Thus, social attitudes involving assertion, self-confidence, autonomy, and empowerment could amplify a woman's use of her literacy skills, and certainly seem to in some social contexts. Furthermore, access to health care due to proximity, status, and income (Fig. 1) can permit a literate woman to use her health skills on behalf of her children's survival. There is, in other words, no escaping the multiple determinations of child health and survival. But literacy might have been a prerequisite for reducing mortality, a necessary but not sufficient condition for the massive declines in the LDCs in the 20th century.

Looking forward, it is important to recognize the limits of women's schooling and the literacy pathway in reducing child mortality and improving child survival. Child mortality can go up as well as down, e.g., because of the spread of incurable diseases, perhaps with declining incomes and deteriorating health care services as additional causes. When Zambia's child mortality rates increased in the 1980s and 1990s, Zambian mothers had primary schooling, they were getting prenatal care themselves and immunizations for their children from nearby clinics, but were unprotected from the infections (HIV/ AIDS, hepatitis B, and drug-resistant malaria) that were posing new threats to child survival. This case calls attention to the contingency of maternal schooling as an influence on child health: it depends on some minimum access to health care of some minimum level of effectiveness. Without access and without effective medicine, even mothers who have been to school will lose children. In many other LDCs, however, it has been observed that sharp declines in income due to economic recession are not followed by an upsurge in child mortality or even an interruption in child mortality decline. This has led Murray and $\mathrm{Chen}^{33}$ to formulate a distinction between stocks and flows among the factors that protect child survival in a society, with stocks being the more stable aspects of the health infrastructure, and flows being those, like income, that are more transient. In this framework, the education level of the population (particularly that of women) and the institutions that support it (schools) would be among the stocks that can maintain a low level of child mortality even when the flows, such as income levels, have gone down. Thus women's schooling, although needing permissive conditions to operate optimally on behalf of child survival, can be a crucial brake on mortality decline when economic conditions deteriorate.

Policy discussions of maternal schooling and child survival inevitably raise the question of whether the schoolsurvival effect can be matched by briefer educational programs for women. School expansion is a long-term policy; in a country with many unschooled and nonliterate women, it could take a generation to increase the stock of schooled women to a level that would bring down a high child mortality rate, and during that time, many children would die. Is it not possible to simulate childhood schooling, and particularly its literacy curriculum, with short-term adult literacy programs? The short answer is no, there are many reasons why adult literacy programs have had little effect and are not promising in terms of health consequences. One reason is that it is difficult for the hardworking women of the LDCs to take time away from home, field, and market for the courses, so they often drop out. Another is that low-intensity adult literacy programs have become institutionalized in many places. The evidence shows that it takes an intensive and extended course to get results, ${ }^{34}$ and such courses are unlikely to be adopted or implemented where they are most needed.

Some sophisticated agencies concerned with child health and mortality like the Center for Global Development now tend to emphasize improving health programs in the near future and demonstrating the dramatic effects of innovative or newly energized grass-roots health interventions. ${ }^{35}$ Women's schooling may have lost its luster as a policy option for improving child health; it may be seen as too diffuse-not targeted on a specific health goal-as well as too long term. However, the evidence reviewed in this article suggests advantages that may not be widely recognized: Low-quality schools have a positive impact on useful maternal literacy and health skills. In the case of literacy, diffuseness is an advantage, because academic language and literacy skills make women more effective at communication not only in clinics and hospitals but also in other bureaucratic settings they may turn to for help in advancing their children's interests. The more we learn about maternal literacy, the more it looks like an indispensable passport to life-saving services for mothers and children in the LDCs.

\section{REFERENCES}

1. Hannum E, Buchmann C. Global educational expansion and socio-economic development: an assessment of findings from the social sciences. World Dev. 2004;33:1-22.

2. Caldwell JC. Education as a factor in mortality decline: an examination of Nigerian data. Popul Stud. 1979;33:395-413.

3. Cochrane SH, O'Hara DJ, Leslie J. The Effects of Education on Health. Staff Working Paper No. 405. Washington, DC: The World Bank; 1980.

4. Moseley WH. Will Primary Health Care Reduce Infant and Child Mortality? In JC Caldwell and G. Santow (eds.), Selected Readings in the Cultural, Social and Behavioural Determinants of Health. Canberra, Australia: Health Transition Centre, Australian National University, 1989, pp. 261-294.

5. Hobcraft JN, McDonald RW, Rutstein SO. Socio-economic factors in infant and child mortality: a cross-national comparison. Popul Stud. 1984;38:193-223.

6. Cleland J, van Ginneken J. Maternal education and child survival in developing countries: the search for pathways of influence. Soc Sci Med. 1988;27:1357-1368.

7. Bicego CT, Boerma JT. Maternal education and child survival: a comparative study of survey data from 17 countries. Soc Sci Med. 1993;36:1207-1227.

8. Hobcraft J. Women's education, child welfare, and child survival: a review of the evidence. Health Transit Rev. 1993;159-175.

9. Jejeebhoy SJ. Women's Education, Autonomy, and Reproductive Behaviour. New York: Oxford University Press; 1995:112.

10. Luther NY, Thapa S. Infant and child mortality in Nepal. EastWest Center Working Paper, Population Series No. 105. Honolulu: East-West Center Press; 1999 
11. Muhuri PK. Health programs, maternal education, and differential child mortality in Matlab, Bangladesh. Popul Dev Rev. 1995;21:813-834.

12. World Development Report 1993: Investing in Health. New York: Oxford University Press; 1993:42-43.

13. Deleted in proof.

14. Hannum E, Buchmann C. Global educational expansion and socio-economic development: an assessment of findings from the social sciences. In: Cohen JE, Bloom DE, Malin MB, eds. Educating All Children: A Global Agenda. Cambridge, MA: The American Academy of Arts and Sciences; 2006:181.

15. Caldwell JC. How is greater maternal education translated into lower child mortality? Health Transit Rev. 1994;4:224-229.

16. Ní Bhrolcháin M, Dyson T. On causation in demography: issues and illustrations. Popul Dev Rev. 2007;33:1-36.

17. Deleted in proof.

18. Wagner D, Venezky R, Street B, eds. Literacy: An International Handbook. Boulder, CO: Westview Press; 1999.

19. Chall J. Stages of Reading Development. New York: McGrawHill; 1996.

20. Snow CE. The development of definitional skill. J Child Lang. 1990;17:697-710.

21. LeVine R, LeVine S, Schnell B. "Improve the women": mass schooling, female literacy and worldwide social change. Harv Educ Rev. 2001;71:1-50.

22. Gorman KS, Pollitt E. The contribution of schooling to literacy in Guatemala. Int Rev Educ. 1997;43:283-298.

23. Deleted in proof

24. Khandke V, Pollitt E, Gorman KS. The role of maternal literacy in child health and cognitive development in rural Guatemala. Poster presented at the Biennial Meetings of the Society for Research in Child Development, 1999.

25. LeVine RA, et al. Literacy and Mothering: How Women's
Schooling Changes the Lives of the World's Children. New York: Oxford University Press. In press.

26. LeVine RA, LeVine SE, Richman A, et al. Women's schooling and child care in the demographic transition: a Mexican case study. Popul Dev Rev. 1991;17:459-496.

27. Dexter ER, LeVine SE, Velasco PM. Maternal schooling and health-related language and literacy skills in rural Mexico. Comp Educ Rev. 1998;42:139-162.

28. Stuebing KW. Maternal schooling and comprehension of chld health information in urban Zambia: is literacy a missing link in the maternal schooling-child health relationship? Health Transit Rev. 1997:151-171.

29. LeVine RA, LeVine SE, Rowe ML, Schnell-Anzola B. Maternal literacy and health behavior: a Nepalese case study. Soc Sci Med. 2004;58:863-877.

30. Schnell-Anzola B, Rowe ML, LeVine RA. Literacy as a pathway between schooling and health-related communication skills: a study of Venezuelan mothers. Int J Educ Dev. 2005;25:19-37.

31. LeVine SE. Getting in, dropping out, and staying on: determinants of girls' school attendance in the Kathmandu Valley of Nepal. Anthropol Educ Q. 2006;37:21-41.

32. Rowe ML, Thapa BJ, LeVine RA, LeVine SE, Tuladhar SK. How does schooling influence maternal health practices? Evidence from Nepal. Comp Educ Rev. 2005;49:512-533.

33. Murray CJL, Chen LC. Dynamics and patterns of mortality change. In: Chen LC, Kleinman A, Ware NC. Health and Social Change in International Perspective. Boston, MA: Harvard School of Public Health; 1994.

34. Comings JP. Literacy skill retention in adult students in developing countries. Int J Educ Dev. 1995; 15:37-45.

35. Levine R; The What Works Working Group. Millions Saved: Proven Successes in Global Health. Washington, DC: Center for Global Development; 2004. 